\title{
Factors Associated with Non-Institutional Delivery among Pregnant Women in Nepal
}

\author{
Jonu Pakhrin Tamang ${ }^{1}$, Rhysa McNeil ${ }^{1,2}, \&$ Phattrawan Tongkumchum ${ }^{1}$ \\ ${ }^{1}$ Faculty of Science and Technology, Prince of Songkla University, Pattani, Thailand \\ ${ }^{2}$ Centre of Excellence in Mathematics, Commission on Higher Education (CHE), Ministry of Education, \\ Ratchathewi, Bangkok, Thailand \\ Correspondence: Rhysa McNeil, Faculty of Science and Technology, Prince of Songkla University, Pattani, \\ Thailand. Tel: 66-87-288-2646. E-mail: nittaya.ch@psu.ac.th
}

Received: April 25, 2019 Accepted: June 17, $2019 \quad$ Online Published: June 30, 2019

doi:10.5539/ass.v15n7p43 URL: https://doi.org/10.5539/ass.v15n7p43

\begin{abstract}
Delivery location may influence maternal morbidity and mortality, especially in developing countries such as Nepal. The aim of this study was to determine factors associated with place of delivery among pregnant women in Nepal in order to inform health policy makers attempting to improve mother and child health. Data from the Multiple Indicator Cluster Survey, conducted in 2014, were retrospectively reviewed. In the survey, women aged 15-49 years were interviewed face-to-face using a structured questionnaire. Study subjects were women who had giving birth within the previous two years. A total of 2,086 women (48.9\%) had non-institutional delivery (46.5\% at home). Logistic regression models were used to identify significant factors influencing non-institutional delivery. Results showed that increasing educational level and wealth quintile index corresponded to a decreasing percentage of non-institutional delivery. More than half $(55.5 \%)$ of women from rural areas had a non-institutional delivery. Multiparous women (57.2\%) and those having less than 4 antenatal care visits (66.8\%) had relatively higher rates of non-institutional delivery. In conclusion, there is a need to intensify education for pregnant women, especially those who have had previous childbirth experience. It is also crucial to target women from poor households, to increase their awareness, and promote institutional delivery.
\end{abstract}

Keywords: logistic regression, maternal and child health, multiple indicator cluster survey, place of delivery

\section{Introduction}

Child bearing is an important life event (Murthy et al., 2007). However, more than one thousand women die each day due to complications of pregnancy and child birth with $99 \%$ of all deaths worldwide occurring in developing countries (World Health Organization, 2015). In sub-Saharan Africa more than 66\% of deliveries have complications, of which $80 \%$ could be averted (World Health Organization, 2015). Most of pregnant women who give birth have complications during pregnancy and delivery (World Health Organization, 2005). The delivery and puerperium periods are unpredictable (Singh, 2009). The delivery location may influence morbidity and mortality of both the mother and child (Darega et al., 2016). The maternal and newborn care received is also related to delivery location (Murthy et al., 2007). In some developing countries, a large proportion of women have non-institutional delivery (Prata et al., 2014). A study from Ethiopia found institutional delivery service utilization was 38.1\% (Ababulgu \& Bekuma, 2016). Other studies from Africa reported institutional delivery utilization rates as low as 10\% (Macro, 2006; Addisalem \& Meaza, 2012). However, studies from Zambia and Malawai reported higher rates of $42.5 \%$ and $58 \%$, respectively (Hazemba \& Siziya, 2008; Martin, 2011). Multiple studies have found a woman's choice of delivery is influenced by several factors, such as her education level, age, ethnicity, area of residence, socio-economic status, antenatal care attendance, parity, and education level of her partner (Abebe et al., 2012; Shrestha et al., 2012; Teferra et al., 2012; Dahal, 2013; Karkee et al., 2013; Sharma et al., 2014; Kebede, 2013; Tsegay, 2013).

In Nepal, fifty percent of deliveries take place at home (HMIS, 2014). The Nepal government has birthing centers within health posts providing 24-hour service to manage uncomplicated deliveries and referral of complicated cases to hospitals, but non-institutional deliveries still comprise half of all deliveries. In Nepal, a cash incentive is given to women who deliver at an institution as a part of a safe delivery program (Bhattarai et al., 2016). However, only $58 \%$ of children born were delivered by a skilled birth attendant and $57 \%$ were 
delivered in a health facility (Ministry of Health and Population, 2016). Therefore, the aim of this study is to determine factors associated with place of delivery among pregnant women in Nepal.

\section{Materials and Methods}

\subsection{Data Source}

Data were reviewed retrospectively from the Multiple Indicator Cluster Survey 2014 (http://mics.unicef.org/surveys), an international multi-stage household survey conducted in 2014 by the Central Bureau of Statistics in collaboration with the United Nations International Children's Emergency Fund. The sampling frame was first stratified into the 15 administrative zones of the country. Thus, the first stage sampling units consisted of 520 census enumeration areas (urban 126, rural 394) and the second stage sampling units consisted of 13,000 households. Systematic random sampling was used in selecting both the enumeration areas and the households. A total of 14,162 women aged 15-49 years were interviewed face-to-face by trained fieldworkers over a 5-month period. Out of these, 2,086 women who had given birth within the past two years of being interviewed were eligible to be selected for this study.

Informed consent was taken before the interview. The ethical approval for the survey was obtained from the Nepal Health Research Council.

\subsection{Study Variables}

The primary outcome for this study is a logical variable indicating whether the woman had a non-institutional delivery for her last child. The identifiable predictors are categorized into three groups: first, socio-demographic characteristics comprising the women's age, education, ethnicity, religion, residential area and region of residence, and household wealth index. The wealth index is a composite indicator calculated from household property such as having means of transport, durable goods, and other facilities in the household. The index was categorized into three groups, namely low, moderate and high representing poor, middle wealth and rich households, respectively. Residential area was either rural or urban. Region of residence was classified into the five Nepalese development regions existing at the time of the survey, namely Eastern, Central, Western, Mid-Western, and Far Western development regions. Second, obstetric characteristics included parity (classified as primipara and multipara), history of child death, and number of antenatal care visits. The World Health Organization (2016) recommends at least four ANC visits within the first four months of pregnancy, therefore the number of antenatal care visits was classified as less than 4 times and more than or equal to 4 times. Frequency of media exposure was defined as how often each woman listened to a radio and/or watched television and was categorized into three groups: not at all, less than weekly and weekly.

\subsection{Statistical Method}

Pearson's chi-squared test was used to identify the bivariate associations between the outcome and each determinant. A multiple logistic regression model was used (Kleinbaum \& Klwin, 2002) which takes the form:

$$
\ln \left(\frac{p_{i}}{1-p_{i}}\right)=\alpha+\sum_{i=1}^{k} \beta_{i} x_{i}
$$

where $p_{i}$ denotes the expected probabilities of experiencing the outcome (in this case non-institutional delivery) for individual $i, \alpha$ is the intercept, $x_{i}$ through to $x_{k}$ refer to the determinants, and $\beta_{i}$ are estimated regression coefficients from the model. Each level of a determinant is compared to the overall percentage of non-institutional delivery and significance is assessed by computing $95 \%$ confidence intervals around the regression coefficients. The adjusted proportions and confidence intervals are computed using weighted sum contrasts (Tongkumchum \& McNeil, 2009). All statistical analyses and graphs were done using R (R Development Core Team, 2016).

\section{Results}

A total of 2,086 women were included in the analysis of which 1,022 (48.9\%) had non-institutional delivery. Table 1 shows the distribution of all factors and their association with the outcome. The majority of women were aged 20-29 years (36.1\%) and had no formal education (39.4\%). Most (67.9\%) were Hindu, and 51.3\% were from a medium wealth index family. Most lived in a rural area $(84.6 \%)$ and $62.4 \%$ were multiparous. More than half (57.3\%) had four or more antenatal care visits during their pregnancy. About half had no previous exposure to electronic media such as radio (48.5\%) and television (53.3\%). All factors except for religion were associated with place of delivery. 
Table 1. Distribution of the determinants and their association with place of delivery

\begin{tabular}{|c|c|c|c|c|}
\hline \multirow[b]{2}{*}{ Determinant } & \multirow{2}{*}{$\begin{array}{c}\text { Total } N=2,086 \\
\text { number }(\%)\end{array}$} & \multicolumn{2}{|c|}{ Place of delivery, n (\%) } & \multirow[b]{2}{*}{ P-value } \\
\hline & & $\begin{array}{c}\text { Institutional } 1,064 \\
(51.1 \%)\end{array}$ & $\begin{array}{c}\text { Non-institutional } 1,022 \\
(48.9 \%)\end{array}$ & \\
\hline Mother's age (years) & & & & 0.01 \\
\hline $13-19$ & $207(9.9)$ & $109(52.7)$ & $98(47.3)$ & \\
\hline $20-24$ & $753(36.1)$ & $409(54.3)$ & $344(45.7)$ & \\
\hline $25-29$ & $661(31.7)$ & $346(52.3)$ & $315(47.7)$ & \\
\hline $30+$ & $465(22.3)$ & $200(43.0)$ & $265(57.0)$ & \\
\hline Mother's education & & & & $<0.01$ \\
\hline None & $822(39.4)$ & $273(33.2)$ & $549(66.8)$ & \\
\hline Primary & 349 (16.7) & $154(44.1)$ & $195(55.9)$ & \\
\hline Secondary & $479(23.0)$ & $302(63.0)$ & $177(37.0)$ & \\
\hline Higher & $436(20.9)$ & $335(76.8)$ & $101(23.2)$ & \\
\hline Ethnicity & & & & 0.002 \\
\hline Brahmin & $628(30.1)$ & $306(48.7)$ & $322(51.3)$ & \\
\hline Chhetri & $279(13.1)$ & $112(40.1)$ & $167(59.9)$ & \\
\hline Janajati & $67(3.2)$ & $37(55.2)$ & $30(44.8)$ & \\
\hline Others & $1,112(53.3)$ & $609(54.8)$ & $503(45.2)$ & \\
\hline Religion & & & & 0.357 \\
\hline Hindu & 1,417 (67.9) & $717(50.6)$ & $700(49.4)$ & \\
\hline Buddhist & $155(7.4)$ & $72(46.5)$ & $83(53.5)$ & \\
\hline Muslim/Christian & $64(3.1)$ & $28(43.8)$ & $36(56.2)$ & \\
\hline Others & $450(22.6)$ & $247(54.9)$ & $203(45.1)$ & \\
\hline Household wealth index & & & & $<0.01$ \\
\hline Poor & $762(36.5)$ & $216(28.3)$ & $546(71.7)$ & \\
\hline Middle & $1,070(51.3)$ & $614(57.4)$ & $456(42.6)$ & \\
\hline Rich & $254(12.2)$ & $234(92.1)$ & $20(7.9)$ & \\
\hline Residential area & & & & $<0.01$ \\
\hline Urban & $343(16.4)$ & $289(84.3)$ & $54(15.7)$ & \\
\hline Rural & $1,743(84.6)$ & $775(44.5)$ & $968(55.5)$ & \\
\hline Development region & & & & $<0.01$ \\
\hline Eastern & 405 (19.4) & $182(44.9)$ & $223(55.1)$ & \\
\hline Central & $432(21.7)$ & $257(59.5)$ & $175(40.5)$ & \\
\hline Western & $319(15.3)$ & $201(63.0)$ & $118(37.0)$ & \\
\hline Mid-western & $377(18.1)$ & $113(30.0)$ & $264(70.0)$ & \\
\hline Far western & $553(26.5)$ & $311(56.2)$ & $242(43.8)$ & \\
\hline Parity & & & & $<0.01$ \\
\hline Primipara & 784 (37.6) & $507(64.7)$ & $277(35.3)$ & \\
\hline Multipara & $1,302(62.4)$ & $557(42.8)$ & $745(57.2)$ & \\
\hline Number of ANC visits & & & & $<0.01$ \\
\hline$<4$ times & $570(27.3)$ & $189(33.2)$ & $381(66.8)$ & \\
\hline$\geq 4$ times & $1,196(57.3)$ & $851(71.2)$ & $345(28.8)$ & \\
\hline Unknown & $320(15.4)$ & $24(7.5)$ & $296(92.5)$ & \\
\hline Radio exposure & & & & $<0.01$ \\
\hline Not at all & $1,012(48.5)$ & $463(45.8)$ & $549(54.2)$ & \\
\hline Less than weekly & $285(14.7)$ & $138(48.4)$ & $147(51.6)$ & \\
\hline Weekly & $789(38.8)$ & $463(58.7)$ & $326(41.3)$ & \\
\hline Television exposure & & & & $<0.01$ \\
\hline Not at all & $1,113(53.3)$ & $385(34.6)$ & $728(65.4)$ & \\
\hline Less than weekly & $160(7.7)$ & $76(47.5)$ & $84(52.5)$ & \\
\hline Weekly & $813(39.0)$ & $603(74.2)$ & $210(25.8)$ & \\
\hline
\end{tabular}




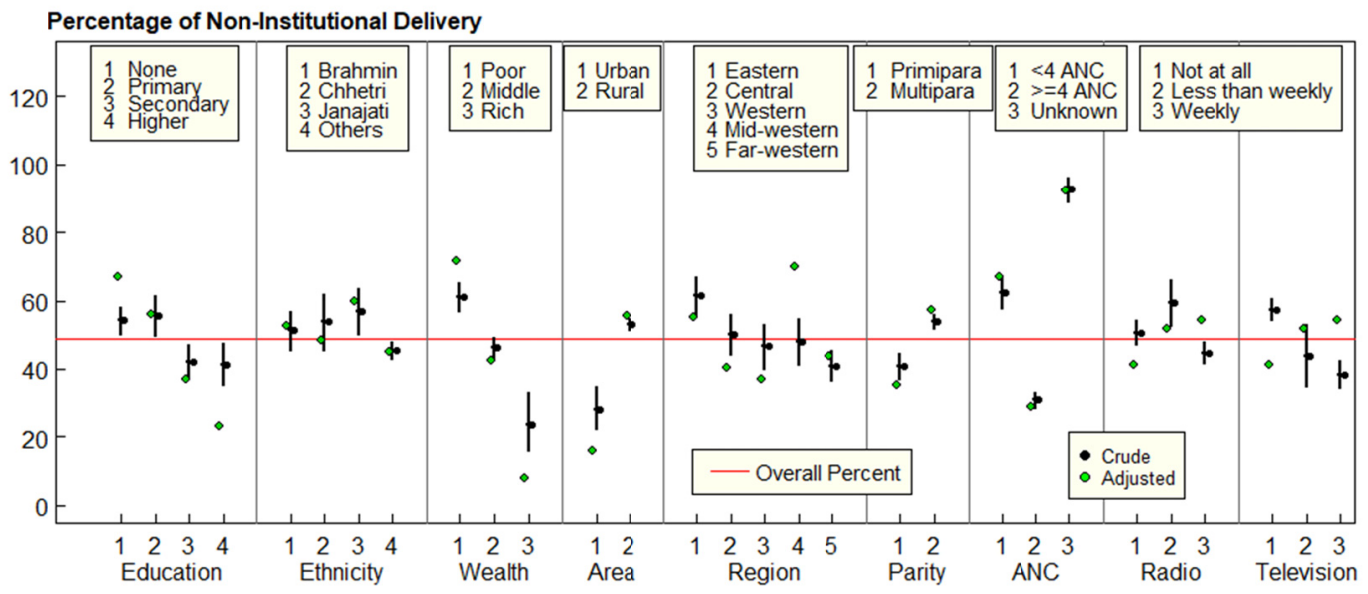

Figure 1. Crude (light dots) and adjusted (dark dots) percentage of non-institutional delivery

Figure 1 shows crude and adjusted percentages with 95\% confidence intervals for women who had non-institutional delivery. The horizontal line is the overall percentage of women who had a non-institutional delivery. The percentage of non-institutional deliveries was higher among women belonging to the Janajati ethnic group compared with women belonging to the Brahmin/Chhetri ethnic group. Lower levels of education and household wealth corresponded to higher percentages of non-institutional delivery after adjusting for other factors. Women from rural areas had a higher percentage of non-institutional delivery as did those from the Eastern Development Region. Multiparity corresponded to a higher percentage of non-institutional delivery. Women who had less than four antenatal care visits and women rarely or not exposed to electronic media such as radio and television had a significantly higher percentage of non-institutional delivery comparing to the overall percentage.

\section{Discussion}

Women with a low education, having low household wealth, living in rural areas and in the Eastern development region, being multiparous, having less than four antenatal care visits and infrequent exposure to electronic media were significantly more likely to have non-institutional delivery. These factors are comparable to those from other developing countries (Gabrysch \& Campbell, 2009; Gabrysch et al., 2011; Mrisho et al., 2007).

This study showed that women of Janajati ethnicity had a higher percentage of non-institutional delivery compared with women of other ethnicities. This may be due to the lower socio-economic status of those of Janajati ethnicity compared to those with Brahmin/Chetri ethnicity (Lynn et al., 2008). Wealth was found to be one of the significant factors for non-institutional delivery in this study, a result similar to a previous study (Shahabuddin et al., 2017). Financial problems were one of the reasons women did not choose a health institutional delivery (Morrison et al., 2014). The results showed that women residing in rural areas were more likely to have non-institutional delivery, a result consistent with a study by Kebede et al. (2016). The study revealed a disparity in the probability of a woman having a non-institutional delivery in different regions. Several international and national organizations focused on improving the health of under five children, pregnant women, and lactating mothers residing in the underdeveloped far western development region of Nepal (USAID, 2005). Women residing in this region are more sensitized and aware of complications during pregnancy and delivery. Therefore, despite it being a mostly rural region, most of the women choose to have institutional delivery. Hence, the percentage of non-institutional delivery in this region is lower compared to the whole country. In contrast, women from the eastern development region had a higher percentage of non-institutional delivery than the whole country.

Studies conducted in Nepal and Bangladesh revealed that under-utilization of antenatal care services (less than four visits) was significantly associated with non-institutional delivery and identified as one of the determining factors which influence the women's preference for place of delivery (Sharma et al., 2014). Antenatal care services ensure opportunities for women by which they receive necessary information. Moreover, multiparous women were more likely to have non-institutional delivery. This result is consistent with studies conducted in Nepal and Pakistan (Dhakal et al., 2011; Agha \& Carton, 2011). Electronic mass media such as radio and television can play a role in disseminating the information on the importance of antenatal care utilization 
focusing on the utilization of health facilities during delivery.

Despite the Nepalese government's efforts to offer free delivery services in Nepal, education, ethnicity, wealth, area and region of residence, parity, antenatal care attendance, and mass media were the major factors which influence women's decision to have non-institutional delivery. Thus, the government should consider investing in innovative ways to increase access to a health facility by pregnant women.

\section{Acknowledgements}

We would like to thank the Centre of Excellence in Mathematics, Commission on Higher Education, Thailand, for providing support for this research.

\section{References}

Ababulgu, F. A., \& Bekuma, TT. (2016). Delivery site preferences and associated factors among married women of child bearing Age in Bench Maji Zone, Ethiopia. Ethiopian Journal of Health Sciences, 26(1), 45-54. http://dx.doi.org/10.4314/ejhs.v25i4.9

Abebe, F., Berhane, Y., \& Girma, B. (2012). Factors associated with home delivery in Bahirdar, Ehiopia: a case control study. BMC Research Notes, 5, 653. https://doi.org/10.1186/1756-0500-5-653

Addisalem, A., \& Meaza, D. (2012). Prevalence of institutional delivery and associated factors in Dodota Woreda (district), Oromia, Regional state, Ethiopia. Reproductive Health, 33(3). https://doi.org10.1186/1742-4755-9-33.

Agha, S., \& Carton, T. W. (2011). Determinants of institutional delivery in rural Jhang, Pakistan. International Journal for Equity in Health, 10(1), 31. https://doi.org10.1186/1475-9276-10-31.

Bhattarai, B. A., Dharel, D., \& Kumar, N. (2016). The safe delivery incentive program in Nepal: towards women's empowerment. International Journal of Medicine and Public Health, 5(10), 2108-2113. https://doi.org10.5455/ijmsph.2016.03032016420.

Dahal, R. K. (2013). Factors influencing the choice of place of delivery among women in eastern rural Nepal. International Journal of Maternal and Child Health, 1(2), 30-37.

Darega, B., Dida, N., Tafese, F., \& Ololo, S. (2016). Institutional delivery and postnatal care services utilizations in Abuna Gindeberet District, West Shewa, Oromiya Region, Central Ethiopia: A Community-based cross sectional study. 2016. BMC Pregnancy Childbirth. https://doi.org/10.1186/s12884-016-0940-x

Dhakal, S., Van Teijlingen, E., Raja, E. A., \& Dhakal, K. B. (2011). Skilled care at birth among rural women in Nepal: practice and challenges. Journal of Health Population and Nutrition, 29(4), 371.

Gabrysch, S., \& Campbell, O. M. (2009). Still too far to walk: Literature review of the determinants of delivery service use. BMC pregnancy and childbirth, 9(1), 34. https://doi.org/10.1186/1471-2393-9-34

Gabrysch, S., Cousens, S., Cox, J., \& Campbell, O. M. (2011). The influence of distance and level of care on delivery place in rural Zambia: A study of linked national data in a geographic information system. PLoS medicine, 8(1), p.e1000394.

Hazemba, A. N., \& Siziya, S. (2008). Prevalence and correlates of utilization health facilities in Chongwe district, Zambia. Medical Journal of Zambia, 35(2), 53-57.

Karkee, R., Binns. C. W., \& Lee, A. H. (2013). Determinants of facility delivery after implementation of safer mother programme in Nepal: A prospective cohort study. BMC pregnancy and childbirth, 13(1), 193. https://doi.org/10.1186/1471-2393-13-193

Kebede, H. (2013). Use of previous maternal health services has a limited role in re-attendance for skilled institutional delivery: Cross-sectional survey in Northwest Ethiopia. International Journal of Women's Health, 5, 79-85.

Kleinbaum, D., \& Klwin, M. (2002). Logistic regression: A self-learning text (2nd ed.). New York, NY: Springer Publishers.

Lynn, B., Dahal, D. R., \& Govindasamy, P. (2008). Caste, ethnic and regional identity in Nepal: Further analysis of 2006 Nepal demographic and health survey. Calverton, Maryland, USA: Macro International Inc.

Macro, O. R. C. (2006). Central Statistical Agency: Ethiopia demographic and health survey 2005. ORC Macro, Calverton, Maryland, USA.

Martin, P. (2011). Determinants of non-institutional deliveries in Malawi. Malawi Medical J., 23(4), 106-108. 
Ministry of Health and Population (MoHP). (2016). Nepal Demographic and Health Survey (NDHS). Population division MoHP, New ERA, Kathmandu, Nepal.

Morrison, J., Thapa, R., Basnet, M., Budhathoki, B., Tumbahangphe, K., Manandhar, A. C., \& Osrin, D. (2014). Exploring the first delay: A qualitative study of home deliveries in Makwanpur district Nepal. BMC Pregnancy Childbirth, 14, 89. https://doi.org/10.1186/1471-2393-14-89

Mrisho, M., Schellenberg, J. A., Mushi, A. K., Obrist, B., Mshinda, H., Tanner, M., \& Schellenberg, D. (2007). Factors affecting home delivery in rural Tanzania. Tropical Medicine and International Health, 12(7), 862-872. https://doi.org/10.1111/j.1365-3156.2007.01855.x.

Murthy, M. S. R., Murthy, P. V., Hari, M., Kumar, V. K. R., \& Rajasekhar, K. (2007). Place of birth: Why urban women still prefer home deliveries. Journal of Human Ecology, 21(2), 149-154. https://doi.org/10.1155/2015/439748.

Prata, N., Bell, S., \& Quaiyum, M. A. (2014). Modeling maternal mortality in Bangladesh: The role of misoprostol in postpartum hemorrhage prevention. BMC pregnancy and childbirth, 14(1), 78. https://doi.org/10.1186/1471-2393-14-78.

R Development Core Team. (2016). R: A Language and Environment for Statistical Computing. R Foundation for Statistical Computing, Vienna, Austria. https://doi.org/10.1038/sj.hdy.6800787

Shahabuddin, A. S. M., Brouwere, V. D., Adhikari, R., Delamou, A., Bardaj, A., \& Delvaux, T. (2017). Determinants of institutional delivery among young married women in Nepal: Evidence from the Nepal demographic and health survey, 2011. BMJ Open, 7, e012446. https://doi.org/10.1136/bmjopen-2016-012446

Sharma, S. R., Poudyal, A. K., Devkota, B. M., \& Singh, S. (2014). Factors associated with place of delivery in rural Nepal. BMC public health, 14(1), 306. https://doi.org/10.1186/1471-2458-14-306.

Shrestha, S. K., Banu, B., Khanom, K., Ali, L., Thapa, N., Stray-Pedersen, B., \& Devkota, B. (2012). Changing trends on the place of delivery: Why do Nepali women give birth at home? Reproductive Health, 9(1), 25. https://doi.org/10.1186/1742-4755-9-25.

Singh, S., Remez, L., Ram, U., Moore, A. M., \& Audam, S. (2009). Barriers to safe motherhood in India. New York: Guttmacher Institute.

Tongkumchum, P., \& McNeil, D. (2009). Confidence intervals using contrasts for regression model. Songklanakarin Journal of Science and Technology, 31(2), 151-156.

Teferra, A. S., Alemu, F. M., \& Woldeyohannes, S. M. (2012). Institutional delivery service utilization and associated factors among mothers who gave birth in the last 12 months in Sekela District, North West of Ethiopia: A community based cross sectional study. BMC Pregnancy Childbirth, 12, 74. https://doi.org/10.1186/1471-2393-12-74.

Tsegay, G. (2013). Determinants of antenatal and delivery care utilization in Tigray region, Ethiopia: A cross-sectional study. Inter. Journal for Equity in Health, 12, 30. https://doi.org/10.1186/1475-9276-12-30.

USAID. (2005). Child Survival in Nepal. Far Western Region Nepal. Retrieved June 9, 2007, from http://pdf.usaid.gov/pdf_docs/Pdaci360.pdf

World Health Organization. (2005). The World Health Report 2005 (pp. 500-507). Make Every Mother and Child Count, Geneva: WHO.

World Health Organization. (2015). Trends in Maternal Mortality: 1990 to 2015. Estimates by WHO, UNICEF, UNFPA.

World Health Organization. (2015). Maternal morality: Fact sheet. Geneva. Retrieved January 1, 2017 from http://www.who.int/mediacentre/factsheets/fs348/en/

World Helath Organization. (2016). WHO recommendations on antenatal care for a positive pregnancy experience. Geneva.

\section{Copyrights}

Copyright for this article is retained by the author(s), with first publication rights granted to the journal.

This is an open-access article distributed under the terms and conditions of the Creative Commons Attribution license (http://creativecommons.org/licenses/by/4.0/). 